\title{
COMPOSIÇÃO QUÍMICA E ATIVIDADE IN VITRO DA PRÓPOLIS BRASILEIRA VERDE E JATAII SOBRE ISOLADOS CLÍNICOS DE Sporothrix brasiliensis
}

\author{
WALLER, Stefanie Bressan ${ }^{1}$; \\ PETER, Cristina Mendes ${ }^{2}$; \\ HOFFMANN, Jéssica Fernanda ${ }^{3}$; \\ OSÓRIO, Luiza da Gama ${ }^{1}$; \\ ZANI, João Luiz ${ }^{2}$; \\ MELLO, João Roberto Braga de ${ }^{4}$; \\ FARIA, Renata Osório de ${ }^{2}$; \\ FISCHER, Geferson ${ }^{2}$.
}

\footnotetext{
${ }^{1}$ Centro de Diagnóstico e Pesquisa em Micologia Veterinária, Faculdade de Veterinária/UFPEL; ${ }^{2}$ Departamento de Veterinária Preventiva, Faculdade de Veterinária/UFPEL, ${ }^{3}$ Laboratório de Cromatografia e Espectrometria de Massas, Faculdade de Agronomia/UFPEL, ${ }^{4}$ Departamento de Farmacologia, Instituto de Ciências Básicas da Saúde/UFRGS.
}

\section{RESUMO}

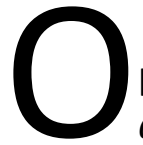
objetivo deste estudo foi avaliar a composição química e a atividade antifúngica da própolis Brasileira Verde (abelhas Apis mellifera) e Jataí (abelhas Tetragonisca angustula) frente ao Sporothrix brasiliensis provenientes de isolados clínicos de cães, gatos e humanos. Os produtos apícolas foram preparados nas formas de extratos hidroalcoólicos, e a composição química foi determinada pela cromatografia líquida de alta eficiência acoplada à espectrometria de massas. A atividade antifúngica sobre $S$. brasiliensis ( $\mathrm{n}$ : 20) foi determinada através da técnica de microdiluição em caldo (M38-A2 do Clinical and Laboratory Standards Institute), adaptado para o uso de produtos naturais. Os extratos apícolas foram testados nas concentrações de 50 a $1,56 \mathrm{mg} / \mathrm{mL}$, e o itraconazol utilizado como controle antifúngico foi testado nas concentrações de 16 a $0,03 \mu \mathrm{g} / \mathrm{mL}$. Os testes foram realizados em duplicatas e os resultados expressos em concentração inibitória mínima (CIM). Na análise química, foi observada um maior conteúdo fenólico total em relação ao conteúdo flavonóide total, para ambos os extratos, havendo um maior conteúdo fenólico na própolis verde. Dos seis ácidos fenólicos e nove flavonóides detectados pela cromatografia, foram quantificados rutina, ácido cafeico, ácido clorogênico, ácido ferúlico e ácido $p$ cumárico, sendo este o último presente em altas concentrações para ambas as amostras, especialmente na própolis verde. Ao avaliar a atividade antifúngica sobre $S$. brasiliensis, nenhum dos extratos apresentou atividade inibitória nas concentrações testadas (CIM >50 $\mathrm{mg} / \mathrm{mL}$ ). Os isolados clínicos apresentaram sensibilidade in vitro ao itraconazol nas CIM >16 a $0,25 \mu \mathrm{g} / \mathrm{mL}$. Entretanto, foram observadas cepas resistentes ao itraconazol.

Palavras-chave: Esporotricose. Resistência antifúngica. Itraconazol. Alternativa terapêutica. Própolis. 


\section{INTRODUÇÃO}

A esporotricose é uma doença infecciosa causada por fungos do complexo Sporothrix schenckii (MARIMON et al., 2007), sendo a espécie Sporothrix brasiliensis de ocorrência frequente nos surtos da doença em felinos no Brasil (MONTENEGRO et al., 2014; SANCHOTENE et al., 2015; WALLER et al., 2016a, 2016b). Essa micose acomete o homem e os animais domésticos através da inoculação traumática acidental com material vegetal contaminado (ARAÚJO et al., 2015) ou pela mordedura/arranhadura de animais doentes, principalmente por felinos domésticos, constituindo uma transmissão zoonótica de importância em saúde pública (MADRID et al., 2012; SILVA et al., 2012; XAVIER et al., 2004).

A doença é caracterizada por lesões nodulares e ulcerativas no tecido subcutâneo, porém, o envolvimento linfático e até mesmo sistêmico pode ocorrer nas formas severas da doença (BARROS et al., 2010; PAIXÃO et al., 2015). O tratamento consiste no uso de medicamentos antifúngicos, sendo o itraconazol considerado o fármaco de eleição (MADRID et al., 2012; ROSSI et al., 2013). Entretanto, o surgimento de isolados fúngicos com capacidade de resistência aos fármacos tem sido relatado (STOPIGLIA et al., 2014; WALLER et al., 2016a, 2016b), alertando para a necessidade da busca por novas moléculas antifúngicas.

Dentre os produtos naturais promissores para a elaboração de fármacos antimicrobianos, estão aqueles de origem apícola, como a própolis, cujas propriedades terapêuticas foram atribuídas aos compostos flavonóides (CUSNHIE; LAMB, 2005; SONMEZ et al., 2005). Tanto a própolis Brasileira produzida por abelhas Apis mellifera, como a própolis verde e vermelha, apresentaram atividade antifúngica contra Candida albicans, C. dubliniensis, C. glabrata, C. krusei, C. parapsilosis, C. tropicalis (FREIRES et al., 2016; PIPPI et al., 2015), Trichophyton spp. (SIQUEIRA et al., 2009), Malassezia pachydermatis (CARDOSO et al., 2010) e Paracoccidioides brasiliensis (SALOMÃO et al., 2004, 2008). Por sua vez, a própolis Jataí, produzida por abelhas Tetragonisca fiebrigi, foi ativa contra C. albicans e C. glabrata (CAMPOS et al., 2015). Há um estudo sobre a sensibilidade in vitro do S. schenckii ao extrato etanólico da própolis Brasileira Verde coletada no Paraná e Minas Gerais (SALOMÃO et al., 2008). Entretanto, não há literatura acerca da atividade antifúngica da própolis brasileira frente ao S. brasiliensis, principal agente nos surtos de esporotricose no Brasil. Assim, este estudo objetivou avaliar a 
atividade anti-Sporothrix brasiliensis das própolis Brasileira Verde e Jataí e suas respectivas constituições químicas.

\section{MATERIAL E MÉTODOS}

\section{Material apícola}

Própolis verde produzida por abelhas $A$. mellifera foi adquirida comercialmente (Néctar Farmacêutica ${ }^{\circledR}$ LTDA, Siderópolis/SC, Brasil), ao passo que a própolis Jataí produzida por abelhas Tetragonisca angustula foi adquirida de um meliponário local (Morro Redondo/RS, Brasil).

\section{Preparo do extrato hidroalcoólico}

Os materiais foram preparados na forma de extratos hidroalcoólicos (PAULINO et al., 2002), sendo previamente congelados a $-70{ }^{\circ} \mathrm{C}$, para posterior trituração. A extração foi realizada em solução contendo álcool $96^{\circ} \mathrm{GL}$ na proporção de 1:3 de própolis para álcool, sob agitação por 24 horas, a $37^{\circ} \mathrm{C}$. O solvente foi evaporado e a matéria seca resultante foi dissolvida em tampão fosfato (pH 7,2) e emulsificada (EUMULGIN ${ }^{\circledR}$ HRE-40), para obtenção da concentração de $100 \mathrm{mg} / \mathrm{ml}$. O composto foi esterilizado em filtro hidrofílico com porosidade de $22 \mu \mathrm{m}$, sendo diluído com água destilada estéril até a concentração de uso.

\section{Análise da constituição química}

A composição química dos extratos de própolis foi determinada por cromatografia líquida, onde $10 \mu \mathrm{l}$ dos extratos foram injetados em cromatógrafo líquido de ultra-alta eficiência (Shimadzu, Prominence) acoplado a um espectrômetro de massas de alta resolução (MicrOTOF-Q, Bruker Daltonics). Os compostos fenólicos foram separados utilizando précoluna C18 $(2,0 \times 4 \mathrm{~mm})$ e coluna Luna C18 $(2,0 \times 150 \mathrm{~mm}, 100 \AA$, $3 \mu \mathrm{m})$ Phenomenex (Torrance, CA, USA). O espectrômetro de massas foi operado no modo ESI negativo, com voltagem do capilar em $4000 \mathrm{~V}$, pressão do gás de nebulização $\left(\mathrm{N}_{2}\right)$ de 2 bar, gás de secagem em 8 L/min e temperatura da fonte de $180{ }^{\circ} \mathrm{C}$, usando os parâmetros padrões do equipamento. $\mathrm{O}$ equipamento foi calibrado com formiato de sódio $10 \mathrm{mM}$, e os espectros de massa foram processados através do software Data Analysis 4.0 (Bruker Daltonics). Para quantificação dos compostos fenólicos e flavonóides, curvas de calibração foram 
preparadas, utilizando os padrões externos de ácido gálico, catequina, ácido 4hidroxibenzóico, ácido clorogênico, epitequina, ácido cafeico, ácido vanílico, ácido siríngico, ácido p-cumárico, ácido ferúlico, rutina, ácido elágico, miricetina, quercetina, hesperetina, kaempferol, luteolina, apigenina, pinocembrina, crisina e galangina, nas concentrações variando de 0 a $10 \mu \mathrm{g} / \mathrm{mL}$. Os compostos fenólicos presentes nas amostras foram caracterizados pela sua UV/Vis $(220-800 \mathrm{~nm})$, e os tempos de retenção calculados em relação aos padrões externos e os espectros de massa.

\section{Atividade anti-Sporothrix brasiliensis}

Para o teste de suscetibilidade antifúngica, foram utilizados 19 isolados clínicos de $S$. brasiliensis, sendo oriundos de gatos ( $n: 9)$ e cães (n: 9) com esporotricose dos municípios de Pelotas e Rio Grande/RS, Brasil, e um isolado de humano ( $n: 1)$, além de uma cepa-padrão de S. brasiliensis (IPEC 16919 - Instituto de Pesquisa Clínica Evandro Chagas, FIOCRUZ, Rio de Janeiro/RJ, Brasil). A identificação fúngica através da análise molecular foi realizada pelo Laboratório de Micologia Médica e Molecular, Universidade Federal de São Paulo (São Paulo/SP, Brasil), por meio da técnica do Polimorfismo no Comprimento de Fragmentos de Restrição (PCR-restriction fragment length polymorphism - RFLP) (RODRIGUES et al., 2014a). Os isolados fúngicos utilizados eram provenientes da micoteca do Centro de Pesquisa e Diagnóstico em Micologia Veterinária, Universidade Federal de Pelotas (Pelotas/RS, Brasil), e eram identificados como s120, s121, s122, s123, s124, s125, s127, s143 e s144 (para isolados felinos) e s10, s53, s74, s89, s101, s104, s114, s126 e s152 (para isolados caninos).

Para a avaliação da suscetibilidade antifúngica, foi realizada a técnica de microdiluição em caldo, de acordo com as diretrizes do Clinical and Laboratory Standards Institute (CLSI, 2008) com adaptações, e os resultados expressos em concentrações inibitórias mínimas (CIM) e concentrações fungicidas mínimas (CFM). Os inóculos fúngicos foram preparados a partir de colônias jovens filamentosas cultivadas em ágar batata-dextrose durante 7 dias a $35{ }^{\circ} \mathrm{C}$ e ajustados em espectrofotômetro (Spectrum Instruments Co., Xangai, China) na transmitância de 80 a $82 \%$ ao comprimento de onda fixado a $530 \mathrm{~nm}$. As suspensões foram diluídas em meio RPMI-1640 (Roswell Park Memorial Institute medium, Sigma, Steinhiem, Alemanha), suplementado com glicose a 2\% e MOPS [ácido 3-(N-morfolino)-propano 
sulfônico] (1:50, v/v). As própolis foram testadas nas concentrações entre 50 a 1,56 mg/mL, e suas diluições foram realizadas seriadamente em RPMI-1640 suplementado sobre microplacas de 96 poços. Para o controle negativo, $200 \mu \mathrm{L}$ de RMPI-1640 suplementado foi adicionado sobre um poço, ao passo que, para o controle positivo, $100 \mu \mathrm{L}$ de RMPI-1640 suplementado e $100 \mu \mathrm{L}$ dos inóculos foram adicionados. Como controle antifúngico, itraconazol (Sporanox ${ }^{\circledR}$, Janssen-Cilag Farmacêutica Ltda., lote TLL 089, São José dos Campos/SP) foi preparado em dimetil-sulfóxido (DMSO), conforme as diretrizes do CLSI, e testados nas concentrações de 16 a 0,03 $\mu \mathrm{g} / \mathrm{mL}$. As microplacas foram incubadas a $27{ }^{\circ} \mathrm{C}$ por 72 horas para leitura dos valores da CIM, e todos os experimentos foram realizados em duplicatas e repetidos duas vezes.

\section{RESULTADOS E DISCUSSÃO}

Através das análises qualitativas e quantitativas dos extratos da própolis Brasileira Verde e jataí (Tabela 1), um maior conteúdo fenólico total em relação ao flavonóide total para ambas as amostras foi observado, o qual é típico nas amostras de própolis amarela, verde, marrom e vermelha do Brasil (MACHADO et al., 2016). Ainda, os conteúdos fenólicos e flavonóides totais foram superiores na própolis Verde em comparação à Jataí, estando em concordância com a literatura (PEREIRA et al., 2002). Considera-se que outros compostos, além de ácidos fenólicos e flavonóides podem estar presentes, pois amostras de própolis produzidas por abelhas T. fiebrigi apresentaram altas quantidades de ácido kaurenóico, retinol, colesterol, tocoferol, cinamil cafeína, entre outros (CAMPOS et al., 2015), podendo estar presentes na amostra Jataí estudada. 
Tabela 1 - Caracterização química das própolis Brasileiras Verde e Jataí e respectivos conteúdos fenólico e flavonóide totais em $\mathrm{mg} / \mathrm{g}$ (média $\pm \mathrm{SD}$ ).

\begin{tabular}{|c|c|c|c|}
\hline \multirow{2}{*}{ Compostos químicos } & \multirow{2}{*}{$\begin{array}{l}\text { Tempo de retenção } \\
\text { (minutos) }\end{array}$} & \multicolumn{2}{|l|}{ Própolis } \\
\hline & & Verde (\%) & Jataí (\%) \\
\hline \multicolumn{4}{|l|}{ Ácidos fenólicos } \\
\hline Ácido gálico & 5.41 & n.d. & n.d. \\
\hline Ácido 4-hidroxibenzóico & 11.17 & + & + \\
\hline Ácido siríngico & 12.45 & n.d. & n.d. \\
\hline Ácido vanílico & 12.12 & n.d. & n.d. \\
\hline Ácido caféico & 12.05 & 0.61 & + \\
\hline Ácido clorogênico & 11.27 & 0.96 & 0.26 \\
\hline Ácido $p$-cumárico & 13.67 & 52.09 & 6.6 \\
\hline Ácido ferúlico & 14.01 & 0.64 & 0.09 \\
\hline Ácido elágico & 15.21 & + & + \\
\hline \multicolumn{4}{|l|}{ Flavonóides } \\
\hline Catequina & 10.25 & n.d. & n.d. \\
\hline Hesperetina & 17.33 & + & + \\
\hline Pinocembrina & 19.49 & + & + \\
\hline Apigenina & 18.24 & + & + \\
\hline Crisina & 20.12 & + & + \\
\hline Luteolina & 17.30 & + & + \\
\hline Epicatequina & 11.74 & n.d. & n.d. \\
\hline Galangina & 20.53 & + & + \\
\hline Kaempferol & 18.00 & + & + \\
\hline Miricetina & 15.52 & n.d. & n.d. \\
\hline Quercetina & 16.89 & + & + \\
\hline Rutina & 14.64 & 3.71 & 0.65 \\
\hline Conteúdo fenólico total ${ }^{a}$ & & $41.84 \pm 5.39$ & $3.93 \pm 0.54$ \\
\hline Conteúdo flavonóide total ${ }^{\mathrm{b}}$ & & $11.40 \pm 1.49$ & $2.05 \pm 0.53$ \\
\hline
\end{tabular}

A composição química entre as própolis foi similar no que tange a avaliação qualitativa, mesmo que produzidas por diferentes espécies de abelhas, o que pode decorrer da planta utilizada para a produção apícola. Sawaya et al. (2004) descreveram que essa similaridade química ocorre porque a principal planta utilizada pelas abelhas $T$. angustula para a produção da própolis Jataí - a Schinus terebinthifolius ou "aroeira-vermelha" - está amplamente presente no território brasileiro e, por esse motivo, também é utilizada pelas abelhas $A$. mellifera para a produção de outras própolis, como a verde. Dos compostos 
avaliados, foram quantificados o flavonóide rutina e os ácidos clorogênico, ferúlico e cafeico em ambas as própolis, além do ácido $p$-cumárico, que também foi majoritário na própolis coletada na Polônia (SOCHA et al., 2015), e cuja atividade antioxidante tem sido relevante.

O ácido p-cumárico tem sido descrito como potencial antifúngico de forma isolada ou em combinação com os ácidos cafeico e dihidrocinânico, induzindo a uma atividade imunomoduladora em monócitos humanos sobre C. albicans (CARDOSO et al., 2017). Além disso, a degradação da parede celular fúngica pelo ácido cafeico e seus derivados já foi demonstrada como mecanismo de ação da atividade antifúngica desses compostos (MA et al., 2010), bem como a ruptura da membrana plasmática (SUNG; LEE, 2010). Esse complexo químico tem sido atribuído à atividade antifúngica das própolis Brasileira Verde e Jataí contra Candida spp. (CAPISTRANO et al., 2013; SALOMÃO et al., 2008) e Trichophyton spp. (NGATU et al., 2012; SIQUEIRA et al., 2009).

Em S. schenckii, os extratos das própolis Brasileira Verde e da própolis Búlgara (SALOMÃO et al., 2008) foram ativos em concentrações seriadas de 16 a $2 \mathrm{mg} / \mathrm{mL}$, promovendo a inibição do crescimento fúngico entre 15 a $25 \mathrm{~mm}$. Embora o estudo tenha atribuído essa atividade à composição majoritária do ácido $p$-cumárico, o mesmo não foi observado sobre os isolados clínicos de S. brasiliensis no nosso estudo (Figura 1), pois não foi observada atividade inibitória nas concentrações testadas das própolis verde e Jataí (CIM>50 mg/mL), mesmo na presença do ácido $p$-cumárico em ambas as amostras. 




Figura 1 - Resultado da atividade in vitro dos extratos hidroalcoólicos da própolis Brasileira Verde (PV) e Jataí (PJ) sobre Sporothrix brasiliensis de origem felina, canina e humana, além da cepa-padrão humana ( $\mathrm{n}: 20)$, demonstrando a ausência de atividade antifúngica nas concentrações testadas de 50 a 1,56 mg/mL (CIM: >50 $\mathrm{mg} / \mathrm{mL})$.

Em relação ao controle antifúngico, os isolados clínicos de $S$. brasiliensis apresentaram uma variação na sensibilidade in vitro ao itraconazol, cujos valores da CIM variaram de 0,03 a maior que $16 \mu \mathrm{g} / \mathrm{mL}$ para os isolados de caninos e felinos. Por sua vez, o isolado clínico humano testado foi sensível na CIM de $16 \mu \mathrm{g} / \mathrm{mL}$, ao passo que a cepa-padrão humana foi a $1 \mu \mathrm{g} / \mathrm{mL}$ (Figura 2). Os resultados demonstraram a ocorrência de resistência ao itraconazol in vitro, seguindo o ponto de corte sugerido pelo documento M38-A2 (CLSI, 2008), o qual designou a sensibilidade ao itraconazol para os isolados de Sporothrix spp. com valores de CIM inferiores a $4 \mu \mathrm{g} / \mathrm{mL}$, e a resistência para os que apresentaram valores de CIM maiores ou iguais a $4 \mu \mathrm{g} / \mathrm{mL}$. Do total de 20 S. brasiliensis testados, 75\% (15/20) foram resistentes in vitro ao itraconazol, alertando para a dificuldade no controle antifúngico, já observadas em casos de esporotricose animal e humana no Brasil (BORBA-SANTOS et al., 2015; RODRIGUES et al., 2014b; WALLER et al., 2016a, 2016b), o que torna necessária a busca por novas moléculas antifúngicas ativas. 


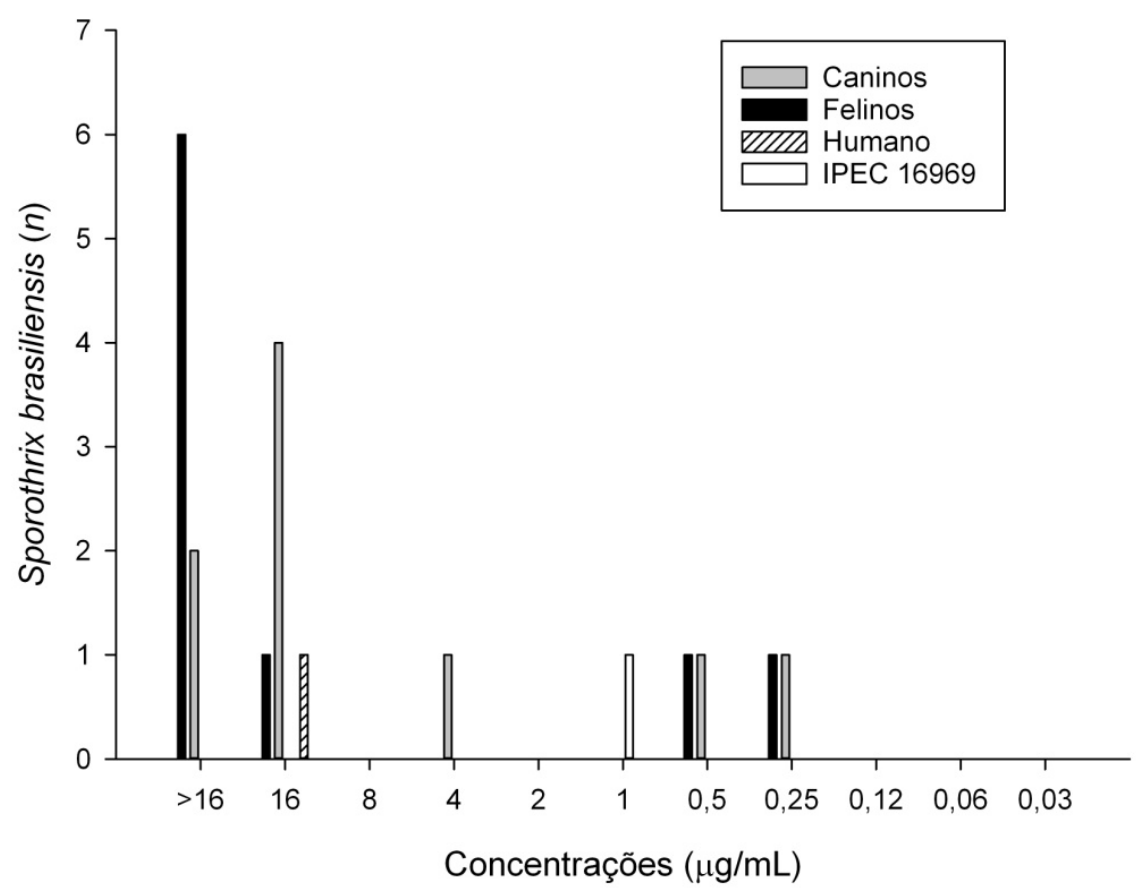

Figura 2 - Resultado da atividade in vitro do itraconazol sobre Sporothrix brasiliensis de origem felina (n: 9), canina (n: 9) e humana ( $n: 1)$, além da cepa-padrão humana (n: 1), indicando atividade antifúngica nas concentrações inibitórias mínimas de $>16$ a $0,25 \mu \mathrm{g} / \mathrm{mL}$.

Embora os produtos não tenham apresentado atividade antifúngica nas concentrações testadas, Waller et al. (2017) demonstraram que o extrato hidroalcoólico da própolis marrom foi ativo sobre S. brasiliensis resistentes ao itraconazol. Assim, supõe-se que o potencial antimicrobiano das diferentes própolis seja dependente da espécie de abelha e das plantas utilizadas para a coleta de pólen (WAGH, 2013), uma vez que as abelhas $A$. mellifera utilizam Baccharis dracunculifolia, popularmente conhecida por alecrim-do-campo (OLIVEIRA et al., 2014), e Eucalyptus sp. (FREITAS et al., 2010) para a produção das própolis verde e marrom, respectivamente. Além disso, a ausência da detecção dos ácidos vanílico e siríngico nas amostras estudadas pode ter influenciado nos resultados, pois foram detectados na própolis marrom ativa (WALLER et al., 2017) e com comprovada atividade antifúngica (MERKL et al., 2010; PANYO et al., 2016). 


\section{CONCLUSÃO}

Os extratos das própolis Brasileiras Verde e Jataí apresentaram análise química similar, com alto conteúdo fenólico total em relação ao conteúdo flavonóide total. $\mathrm{Na}$ análise quantitativa, observou-se a composição majoritária do ácido p-cumárico. Na atividade antifúngica, os extratos de ambas as própolis não foram ativos sobre $S$. brasiliensis nas concentrações testadas. Em relação ao itraconazol, observou-se a presença de S. brasiliensis resistentes ao itraconazol.

\section{CHEMICAL COMPOSITION AND IN VITRO ACTIVITY OF GREEN AND JATAÍ BRAZILIAN PROPOLIS ON CLINICAL ISOLATES OF Sporothrix brasiliensis}

\section{ABSTRACT}

$\mathrm{T}$

he aim of this study was to evaluate the chemical composition and antifungal activity of Green (bee Apis mellifera) and Jataí (bee Tetragonisca angustula) Brazilian propolis against Sporothrix brasiliensis obtained from clinical isolates of dogs, cats and humans. The products were prepared as hydroalcoholic extracts, and the chemical composition was analyzed by high efficiency liquid chromatography coupled with a mass spectrometer. The antifungal activity on S. brasiliensis ( $\mathrm{n}$ : 20) was determined through the broth microdilution technique (M38-A2 document of Clinical and Laboratory Standards Institute), adapted to natural products. The extracts were tested from the concentrations of 1.56 to $50 \mathrm{mg} / \mathrm{mL}$, and itraconazole was used as antifungal control from 0.03 to $16 \mu \mathrm{g} / \mathrm{mL}$. The tests were performed in duplicate and the results were expressed in minimal inhibitory concentrations (MIC). In the chemical analysis, a higher total phenolic content in relation to total flavonoid content was observed for both extracts, with a higher phenolic content in the green propolis. Among the six phenolic acids and nine flavonoids detected by chromatography, rutin, cafeic acid, chlorogenic acid, ferulic acid and $p$-coumaric acid were the compounds quantified, being this last compound present in high concentrations for both samples, mainly in green propolis. In the antifungal activity on S. brasiliensis, none of the extracts showed inhibitory activity in the tested concentrations (MIC $>50 \mathrm{mg} / \mathrm{mL}$ ). The clinical isolates showed in vitro sensibility to itraconazole in the MIC up to 16 to $0,25 \mu \mathrm{g} / \mathrm{mL}$, but itraconazoleresistant isolates were observed.

Keywords: Sporotrichosis. Antifungal resistance. Itraconazole. Therapeutic alternative. Propolis. 


\section{COMPOSICIÓN QUÍMICA Y ACTIVIDAD IN VITRO DE PROPÓLEO VERDE Y JATAÍ DE BRASIL EN AISLAMIENTOS CLÍNICOS DE Sporothrix brasiliensis}

\section{RESUMEN}

L objetivo del estudio fue evaluar la composición química y la actividad antifúngica de - propóleos Brasileños Verde (abejas Apis mellifera) y Jataí (abejas Tetragonisca angustula) contra Sporothrix brasiliensis a partir de aislados clínicos de perros, gatos y seres humanos. Los productos fueron preparados en forma de extractos hidroalcohólicos y la composición química fue determinada por cromatografia líquida de alta resolución acoplada a espectrometría de masas. La actividad antifúngica contra S. brasiliensis (n: 20) fue determinada por la técnica de microdilución en caldo (M38-A2 do Clinical and Laboratory Standards Institute), adaptado para el uso de productos naturales. Los extractos de propóleos fueron evaluados en concentraciones de 50 a $1,56 \mathrm{mg} / \mathrm{mL}$ y el itraconazol utilizado como un control antifúngico fue testado en concentraciones de 16 a 0,03 $\mathrm{\mu g} / \mathrm{mL}$. Los tests fueron realizados por duplicado y los resultados se expresaron como concentración inhibitoria mínima (CIM). En el análisis químico, un mayor contenido total fenólico en relación al contenido total de flavonoides se observó para ambos extractos, con un mayor contenido fenólico en propóleo verde. De los seis ácidos fenólicos y nueve flavonoides detectados por cromatografía, los compuestos cuantificados fueron rutin, ácido clorogénico, ácido cafeico, ácido ferúlico y ácido $p$-cumárico. Este último compuesto estaba presente en altas concentraciones para ambas muestras, especialmente en propóleo verde. Al evaluar la actividad antifúngica contra $S$. brasiliensis, ninguno de los extractos mostraron actividad inhibitoria en las concentraciones (CIM $>50 \mathrm{mg} / \mathrm{mL}$ ). Los aislados clínicos mostraron susceptibilidad in vitro al itraconazol en las $\mathrm{CIM}>16$ a $0,25 \mu \mathrm{g} / \mathrm{mL}$. Sin embargo, se observaron aislados resistentes a itraconazol.

Palabras clave: Esporotricosis. Resistencia antimicótica. Itraconazol. Terapia alternativa. Propóleo.

\section{AGRADECIMENTOS}

Os autores agradecem a Dr. Zoilo Pires de Camargo (Universidade Federal de São Paulo UNIFESP, São Paulo/SP, Brasil) pela análise biomolecular dos isolados fúngicos. 


\section{REFERÊNCIAS}

ARAÚJO, M. L.; RODRIGUES, A. M.; FERNANDES, G. F.; et al. Human sporotrichosis beyond the epidemic front reveals classical transmission types in Espírito Santo, Brazil. Mycoses, v. 58, n. 8, p. 485-490, 2015.

BARROS, M. B. L.; SCHUBACH, T. M. P.; COLL, J. O.; et al. Esporotricose: a evolução e os desafios de uma epidemia. Revista Panamericana de Salud Publica, v. 27, n. 6, p. 455-460, 2010.

BORBA-SANTOS, L. P.; RODRIGUES, A. M.; GAGINI, T. B.; FERNANDES, G. F.; CASTRO, R.; et al. Susceptibility of Sporothrix brasiliensis isolates to amphotericin B, azoles, and terbinafine. Medical Mycology, v. 53, n. 2, p. 178-188, 2015.

CAMPOS, J. F.; DOS SANTOS, U. P.; DA ROCHA, P. D. O. S.; et al. Antimicrobial, Antioxidant, Anti-Inflammatory, and Cytotoxic Activities of Propolis from the Stingless Bee Tetragonisca fiebrigi (Jataí). Evidence-Based of Complementary Alternative Medicine, v. 2015, article ID. 296186, 11p, 2015.

CAPISTRANO, H. M.; DE ASSIS, E. M.; LEAL, R. M.; et al. Brazilian green propolis compared to miconazole gel in the treatment of Candida-associated denture stomatitis. Evidence-Based of Complementary Alternative Medicine, v. 2013, article ID 947980, 6p, 2013.

CARDOSO, E. O.; CONTI, B. J.; SANTIAGO, K. B.; et al. Phenolic compounds alone or in combination may be involved in propolis effects on human monocytes. Journal of Pharmacy and Pharmacology, v. 69, n. 1, p. 99-108, 2017.

CARDOSO, R. L.; MABONI. F.; MACHADO, G.; et al. Antimicrobial activity of propolis extract against Staphylococcus coagulase positive and Malassezia pachydermatis of canine otitis. Veterinary Microbiology, v. 142, n. 3-4, p. 432-434, 2010.

CLSI - Clinical and Laboratory Standards Institute. Reference Method for Broth Dilution Antifungal Susceptibility Testing of Filamentous Fungi. Approved Standard, 3. ed. CLSI publication M38-A2, 2008.

CUSNHIE, T. P. T.; LAMB, A. J. Antimicrobial activity of flavonoids. International Journal of Antimicrobial Agents, v. 26, p. 343-356, 2005.

FREITAS, A. S.; BARTH, O. M.; PINTO, C. F. Brownish propolis from the Atlantic coastal areas in the state of Rio de Janeiro, Brazil: a palynological approach. Brazilian Journal of Botany, $\mathrm{v}$. 33, n. 2, p. 343-354, 2010.

FREIRES, I. A.; QUEIROZ, V. C.; FURLETTI, V. F.; et al. Chemical composition and antifungal potential of brazilian propolis against Candida spp. Journal de Mycologie Médicale, v. 26, n. 2, p. 122-132, 2016. 
MA, C. M.; ABE, T.; KOMIYAMA, T.; et al. Synthesis, anti-fungal and 1,3-beta-D-glucan synthase inhibitory activities of caffeic and quinic acid derivatives. Bioorganic \& Medicinal Chemistry, v. 18, n. 19, p. 7009-7014, 2010.

MACHADO, C. S.; MOKOCHINSKI, J. B.; LIRA, T. O.; et al. Comparative study of chemical composition and biological activity of yellow, green, brown, and red Brazilian Propolis. Evidence-Based of Complementary Alternative Medicine, v. 2016, article ID 6057650, 11p, 2016.

MADRID, I. M.; MATTEI, A. S.; FERNANDES, C. G.; et al. Epidemiological Findings and Laboratory Evaluation of Sporotrichosis: A Description of 103 Cases in Cats and Dogs in Southern Brazil. Mycopathologia, v. 173, n. 4, p. 265-273, 2012.

MARIMON, R.; CANO, J.; GENE, J.; et al. Sporothrix brasiliensis, S. globosa and S. mexicana, three new Sporothrix species of clinical interest. Journal of Clinical Microbiology, v. 45, n. 10, p. 3198-3206, 2007.

MERKL, R.; HRÁDKOVÁ, I.; FILIP, V.; et al. Antimicrobial and Antioxidant Properties of Phenolic Acids Alkyl Esters. Czech Journal of Food Sciences, v. 28, n. 4, p. 275-279, 2010.

MONTENEGRO, H.; RODRIGUES, A. M.; DIAS, M. A. G.; et al. Feline sporotrichosis due to Sporothrix brasiliensis: an emerging animal infection in São Paulo, Brazil. BMC Veterinary Research, v. 269, p. 1-10, 2014.

NGATU, N. R.; SARUTA, T.; HIROTA, R.; et al. Brazilian green propolis extracts improve Tinea pedis interdigitalis and Tinea corporis. Journal of Alternative and Complementary MedicinE, v. 18, n. 1, p. 8-9, 2012.

OLIVEIRA, P. F.; SOUZA LIMA, I. M.; MUNARI, C. C.; et al. Comparative evaluation of antiproliferative effects of Brazilian green propolis, its main source Baccharis dracunculifolia, and their major constituents artepillin C and baccharin. Planta Medica, v. 80, n. 6, p. 490492, 2014.

PAIXÃO, A. G.; GALHARDO, M. C. G.; ALMEIDA-PAES, R.; et al. The difficult management of disseminated Sporothrix brasiliensis in a patient with advanced AIDS. AIDS Research and Therapy, v. 12, p. 12-16, 2015.

PANYO, J.; MATSUNAMI, K.; PANICHAYUPAKARANANT, P. Bioassay-guided isolation and evaluation of antimicrobial compounds from Ixora megalophylla against some oral pathogens. Pharmaceutical Biology, v. 54, n. 9, p. 1522-1527, 2016.

PAULINO, P.; SCRIMIM, F. M.; RAICHASKI, L. B.; et al. Mechanisms involved in the relaxant action of the ethanolic extract of propolis in the guinea-pig trachea in-vitro. Journal of Pharmacy and Pharmacology, v. 54, p. 845-852, 2002. 
PEREIRA, A. S.; SEIXAS, F. R. M. S.; AQUINO NETO, F. R. Própolis: 100 anos de pesquisa e suas perspectivas futuras. Química Nova, v. 25, p. 321-326, 2002.

PIPPI, B.; LANA, A. J. D.; MORAES, R. C.; et al. In vitro evaluation of the acquisition of resistance, antifungal activity and synergism of Brazilian red propolis with antifungal drugs on Candida spp. Journal of Applied Microbiology, v. 118, p. 839-850, 2015.

RODRIGUES, A. M.; HOOG, G. S.; CAMARGO, Z. P. Genotyping species of the Sporothrix schenckii complex by PCR-RFLP of calmodulin. Diagnostic Microbiology and Infectious Disease, v. 78, p. 383-387, 2014a.

RODRIGUES, A. M.; HOOG, G. S.; PIRES, D. C.; et al. Genetic diversity and antifungal susceptibility profiles in causative agents of sporotrichosis. BMC Infectious Disease, v. 14, p. 219, 2014b.

ROSSI, C. N.; ODAGUIRI, J.; LARSSON, C. E. Retrospective assessment of the treatment of sporotrichosis in cats and dogs using itraconazole. Acta Scientiae Veterinariae, v. 41, p. 1112, 2013.

SALOMÃO, K.; DANTAS, A. P.; BORBA, C. M.; et al. Chemical composition and microbicidal activity of extracts from Brazilian and Bulgarian propolis. Letters of Applied Microbiology, v. 38, p. 87-92, 2004.

SALOMÃO, K.; PEREIRA, P. R. S.; CAMPOS, L. C.; et al. Brazilian Propolis: Correlation between Chemical Composition and Antimicrobial Activity. Evidence Based of Complementary Alternative Medicine, v. 5, n. 3, p. 317-324, 2008.

SANCHOTENE, K. O.; MADRID, I. M.; KLAFKE, G. B.; et al. Sporothrix brasiliensis outbreaks and the rapid emergence of feline sporotrichosis. Mycoses, v. 58, n. 11, p. 652-658, 2015.

SAWAYA, A. C. H. F.; TOMAZELA, D. M.; CUNHA, I. B. S.; et al. Electrospray ionization mass spectrometry fingerprinting of propolis. The Analyst, v. 129, p. 739-744, 2004.

SILVA, D. T.; MENEZES, R. C.; GREMIÃO, I. D. F.; et al. Zoonotic sporotrichosis: biosafety procedures. Acta Scientiae Veterinariae, v. 40, n. 4, p. 1067, 2012.

SIQUEIRA, A. B. S.; GOMES, B. S.; CAMBUIM, I.; et al. Trichophyton species susceptibility to green and red propolis from Brazil. Letters in Applied Microbiology, v. 48, p. 90-96, 2009.

SOCHA, R.; GALKOWSKA, D.; BUGAJ, M.; JUSZCZAK, L. Phenolic composition and antioxidant activity of propolis from various regions of Poland. Natural Products Research, v. 29, n. 5, p. 416-422, 2015. 
SONMEZ, S.; KIRILMAZ, L.; YUCESOY, M.; et al. The effect of bee propolis on oral pathogens and human gingival fibroblast. Journal of Ethnopharmacology, v. 102, p. 371-376, 2005.

STOPIGLIA, C. D. O.; MAGAGNIN, C. M.; CASTRILLON, M. R.; et al. Antifungal susceptibilities and identification of species of the Sporothrix schenckii complex isolated in Brazil. Medical Mycology, v. 52, p. 56-64, 2014.

SUNG, W. S.; LEE, D. G. Antifungal action of chlorogenic acid against pathogenic fungi, mediated by membrane disruption. Pure and Applied Chemistry, v. 82, p. 219-226, 2010.

WAGH, V. D. Propolis: a wonder bees products and its pharmacological potentials. Advances in Pharmacological Sciences, v. 2013, article ID 308249, 11p, 2013.

WALLER, S. B.; MADRID, I. M.; FERRAZ, V.; et al. Cytotoxicity and anti-Sporothrix brasiliensis activity of the Origanum majorana Linn. oil. Brazilian Journal of Microbiology, v. 47, p. 896901, 2016a.

WALLER, S. B.; MADRID, I. M.; SILVA, A. L.; et al. In Vitro Susceptibility of Sporothrix brasiliensis to Essential Oils of Lamiaceae Family. Mycopathologia, v. 181, n. 11-12, p .857$863,2016 b$.

WALLER, S. B.; PETER, C. M.; HOFFMANN, J. F.; et al. Chemical and cytotoxic analyses of brown Brazilian propolis (Apis mellifera) and its in vitro activity against itraconazole-resistant Sporothrix brasiliensis. Microbial Pathogenesis, v. 105, p. 117-121, 2017.

XAVIER, M. O.; NOBRE, M. O.; SAMPAIO JR., D. P.; et al. Esporotricose felina com envolvimento humano na cidade de Pelotas, RS, Brasil. Ciência Rural, v. 34, p. 1961-1963, 2004. 